Research Article

\title{
Sensitivity of Nanostructured Mn-Doped Cobalt Oxide Films for Gas Sensor Application
}

\author{
Ehssan Salah Hassan ${ }^{1}$, Kameran Yasseen Qader ${ }^{2}$, Esraa Hassn Hadi $^{2}$, Sami Salman Chiad ${ }^{2}$, Nadir \\ Fadhil Habubi $^{2}$, Khalid Haneen Abass ${ }^{3 \longleftarrow}$ \\ ${ }^{1}$ Department of Physics, College of Science, Mustansiriyah University, Baghdad, Iraq. \\ ${ }^{2}$ Department of Physics, College of Education, Mustansiriyah University, Baghdad, Iraq. \\ ${ }^{3}$ Department of Physics, College of Education for Pure Sciences, University of Babylon, Iraq. \\ Corresponding authors. E-mail: nadirfadhil@uomustansiriyah.edu.iq; pure.khalid.haneen@uobabylon.edu.iq
}

Received: Mar. 19, 2020; Accepted: Jun. 20, 2020; Published: Jul. I3, 2020

Citation: Ehssan Salah Hassan, Kameran Yasseen Qader, Esraa Hassn Hadi, Sami Salman Chiad, Nadir Fadhil Habubi, and Khalid Haneen Abass, Sensitivity of Nanostructured Mn-Doped Cobalt Oxide Films for Gas Sensor Application. Nano Biomed. Eng., 2020, I2(3): $205-213$.

DOI: $10.5101 /$ nbe.v12i3.p205-213.

\begin{abstract}
The effect of manganese doped cobalt oxide $\left(\mathrm{Co}_{3} \mathrm{O}_{4}: \mathrm{Mn}\right)$ was investigated by two different ratios ( $1 \%$ and $3 \%$ ), which were precipitated by spray pyrolysis technique (SPT), and was adopted using a laboratory designed glass atomizer. Glass substrates were used to deposit films on them, heated at a temperature of $420^{\circ} \mathrm{C}$. The structural properties were studied through X-ray diffraction. The results showed that all deposit nanostructured films were polycrystalline and there was a decrease in the preferred reflection intensity along (311) plane resulting in a decrease in the crystallite size. Surface properties were analyzed through atomic force microscopy (AFM), which showed a decrease in the roughness and the particle size growth was a vertical columnar rod. The optical characterization displayed that the transmittance of pure $\mathrm{Co}_{3} \mathrm{O}_{4}$ nanostructured films was $48 \%$ and decreased to $35 \%$ for $1 \%$ of the $\mathrm{Mn}$ concentration, and continued to decrease to $33 \%$ with the increase of manganese concentration up to $3 \%$. Optical energy bandgap of pure $\mathrm{Co}_{3} \mathrm{O}_{4}$ nanostructured films was $1.435 \mathrm{eV}$ and decreased to $1.419 \mathrm{eV}$ for $1 \%$ of $\mathrm{Mn}$ concentration, and continued to decrease to $1.367 \mathrm{eV}$ with the increase of $\mathrm{Mn}$ concentration up to $3 \%$. The highest percentage sensitivity was for the sample doped with $3 \% \mathrm{Mn}$, which was about $65 \%$, for $\mathrm{NO}_{2}$ gas concentration of $600 \mathrm{ppm}$, at an operating temperature of $200^{\circ} \mathrm{C}$.
\end{abstract}

Keywords: Manganese, Cobalt oxide, SPT, Crystalite size, Columnar rod, Gas sensor

\section{Introduction}

Among the different transition metal oxides (TMO), $\mathrm{Co}_{3} \mathrm{O}_{4}$ is an imperative p-type semiconductor (coordinate energy bandgap at 1.48 and $2.19 \mathrm{eV}$ ) [1, 2]. Generally utilized as an electrochemical gadget [3], heterogeneous impetus [4], gas sensor [5], anode material in lithium batteries [6], and sunlight based vitality safeguard [7].
Recently the consideration regarding transition metal oxides has been taken into account. Metal oxide nanostructures play an essential role in numerous locales of science, physical science, ecological science, and material science [8-10]. These TMO, while falling in the nano estimated administration, are relied upon to have significantly witnessed an increasing interest in the fields; for example, information stockpiling, spintronics biomedicine, and 
broadcast communications [11-14]. These features are firmly subject to their dimension and surface properties. The $\mathrm{Co}_{3} \mathrm{O}_{4}$ shows an ordinary spinal structure, in which $\mathrm{Co}^{2+}$ is engaged in tetrahedral destinations and $\mathrm{Co}^{3+}$ is engaged in octahedral locales [15]. This is very attractive because of the twists of $\mathrm{Co}^{2+}$ particles, with a little commitment from turn circle coupling. Then again, $\mathrm{Co}^{3+}$ particles have no perpetual attractive point as a result of the part of $3 \mathrm{D}$ levels of the octahedral precious stone field and finish filling of levels [16]. Given the attractive properties of permeable $\mathrm{Co}_{3} \mathrm{O}_{4}$ small scale $3 \mathrm{D}$ squares, the antiferromagnetic $\mathrm{Co}_{3} \mathrm{O}_{4}$ displays a specific level of ferromagnetism under outside attractive field because of the unpaired particles' closeness to the surface of the nanocrystals and the association of molecules. The unique properties of nanoparticle unequivocally reliant change of shapes and sizes and crystallization, charge heading [17]. Recently, a few procedures have been utilized to enhance the conduct of metal oxides by methods for presenting different dopants [18], shaping nanocomposites with p-n intersection [19], and by tuning the morphology [7], have focused on the electrical and surface properties of nanoparticles to accomplish enhanced reactant, electro-optical, attractive, substance, and physical properties [20]. $\mathrm{Co}_{3} \mathrm{O}_{4}$ :Mn produced by solgel spin coat method has polycrystalline nature with degradation in the crystallization with increased manganese concentration, and the output phase is cubic with the appearance of orthorhombic $\mathrm{MnO}_{2}$ phase. Shan, and Dai [21] explained that the doping of cobalt by magnesium causes a decrease in particle size and most particles had a nano-spherical shape and the size were between 82-244 nm. In this research Mn doped cobalt oxide is prepared to study their physical properties to use these films as a gas sensor [22-24]. The PLAL synthesized $\mathrm{MoS}_{2}$ NS explained the vast absorbance in Vis region. Photocatalytic activity of $\mathrm{TiO}+-\mathrm{ZSM}_{5}-\mathrm{MoS}_{2}$ nanocomposite was examined with arsenite. $\mathrm{TiO}_{2}-\mathrm{ZSM}_{5}-\mathrm{MoS}_{2}$ nanocomposite displayed nearly $100 \%$ arsenic photo-conversion to Usenet. This work aims to consider the effect of deformation on the sensitivity of the deposited films for $\mathrm{NO}_{2}$ gas.

\section{Experimental}

An aqueous solution of $0.1 \mathrm{M}$ of $\mathrm{CoCl}_{2} \cdot 6 \mathrm{H}_{2} \mathrm{O}$ supplied from Merck Chemicals (Germany) was used to prepare thin films of $\mathrm{Co}_{3} \mathrm{O}_{4}$ [25], and $0.1 \mathrm{M}$ of
Manganese chloride $\mathrm{MnCl}_{2} \cdot 4 \mathrm{H}_{2} \mathrm{O}$ was used as doping agent with a concentration of $1 \%$ and $3 \%$ to obtain $\mathrm{Mn}$ doped cobalt chloride [26]. A few drops of $\mathrm{HCl}$ were added to obtain a homogeneous solution. The spray pyrolysis technique was adopted with an experimental intended glass spray [27]. Glass substrate was used for deposition heated at a temperature of $420{ }^{\circ} \mathrm{C}$. The following optimal status was taken into account, with spray time of $8 \mathrm{~s}$. The spray was sprayed with two limits of $1.5 \mathrm{~min}$ to avoid excessive cooling and to prevent cracks. Nitrogen carrier gas was upheld at a pressure of $10^{5} \mathrm{Nm}^{-2}$. The space between the nozzle and the substrate was $28 \pm 1 \mathrm{~cm}$, at solution flow rate of $4 \mathrm{~mL} / \mathrm{min}$. Film thickness was dignified using gravimetric process and was found to be about 320 $\mathrm{nm}$. Optical transmittance and absorbance employing UV-visible spectrophotometer were verified in the wavelengths range of 300-1100 nm (Shimadzu Company, Japan). High accuracy XRD was utilized to investigate the structural qualifications of thin films employing D8 Advance Bruker system, $\operatorname{CuK} \alpha(\lambda=$ $0.154056 \AA$ ).

\section{Results and Discussion}

XRD spectra of pure and $\mathrm{Mn}: \mathrm{Co}_{3} \mathrm{O}_{4}$ nanoparticles are illustrated in Fig. 1(a), (b) and (c), from which the phase and crystalline structure were diagnosed. The samples were polycrystalline with a clear difference in intensity of reflections from crystalline levels for all diffraction peaks. The preferred reflection was (311) plane at $2 \theta=36.92^{\circ}$, with several secondary reflections of (220), (222), (400), (511) and (440) at $2 \theta=31.27^{\circ}$, $38.32^{\circ}, 44^{\circ}, 60.12^{\circ}$ and $56.19^{\circ}$ respectively. These results assured predominant of the cubic phase with no reflections for any phases concerning manganese. These peaks were in a perfect match with JCPDS data (JCPDS Card No. 43-1003) [28]. Note that the effect doping concentrations increasing up to $3 \%$ did not change the phase of cobalt oxide, and these were the most important conditions of doping, as well as through the alteration in intensity of scattering for the peaks produced. The doping of ions with a smaller ionic radius $\mathrm{Mn}^{2+}(0.80 \AA)$ than the host material $\mathrm{Co}^{2+}$ $(0.72 \AA)$ led to a change in the values of lattice constant which could be followed by a deviation in the angle of reflection of the preferred plane towards the smaller angle. A noticeable decrease in the intensity of the preferred reflection (311) plane as shown in Fig. 1(d), (e) and (f) indicated an increase in the lattice constant. 


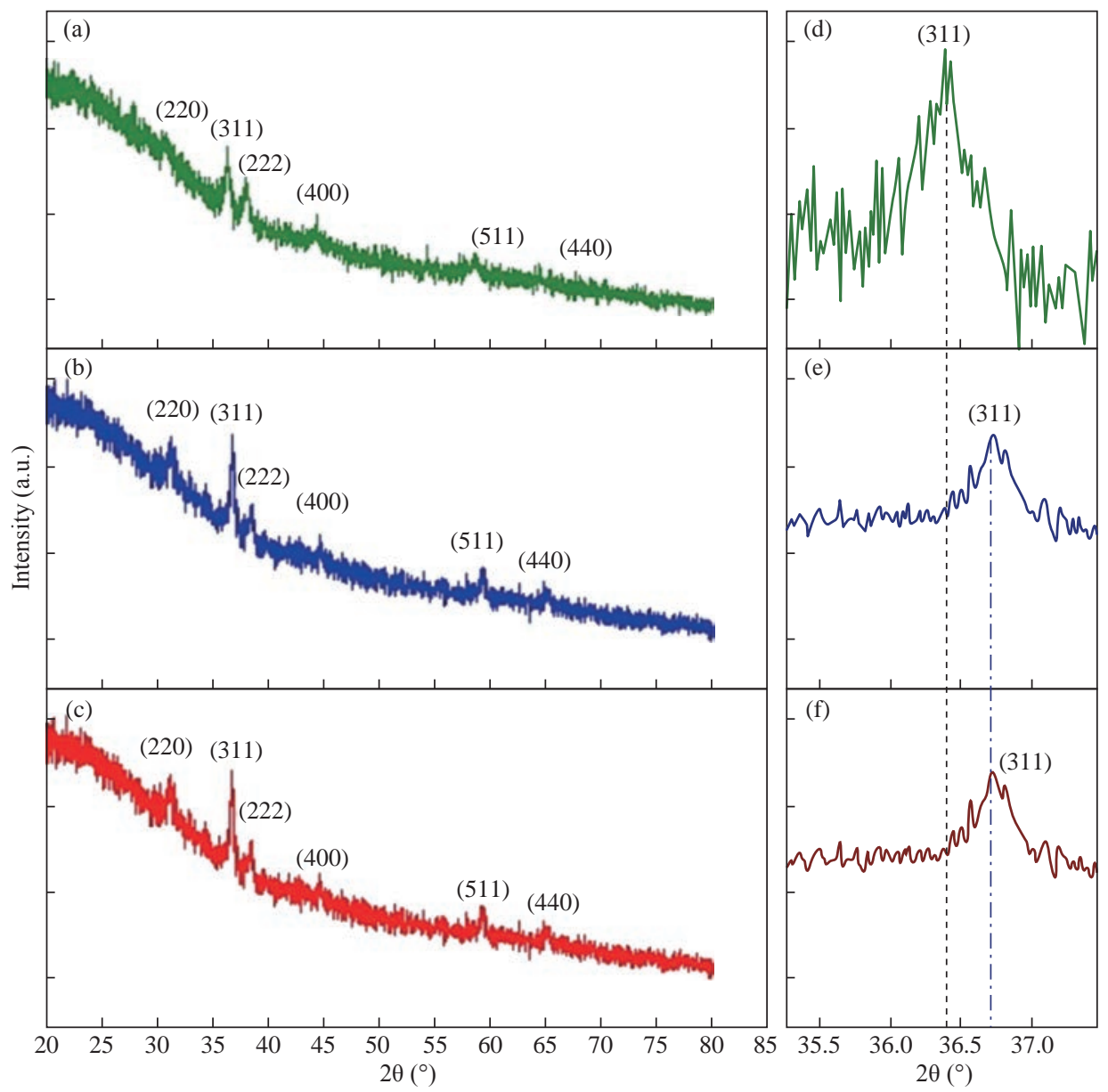

Fig. 1 XRD patterns of (a) pure $\mathrm{Co}_{3} \mathrm{O}_{4}$, (b) $1 \%$ and (c) $3 \%$ Mn doped $\mathrm{Co}_{3} \mathrm{O}_{4}$, (d)-(f) drift in $2 \theta$ of the preferred plane of pure, $1 \%$ and $3 \% \mathrm{Mn}$ doped $\mathrm{Co}_{3} \mathrm{O}_{4}$, respectively.

Fig. 2 offers the crystallite size of the prepared films considered from the FWHM witch represented the full width of high maximum; $(\beta)$ for higher intensity (311) plane by applying Scherrer's Equation (1) [29] showed a decrease in crystallite size (D) via an increase in doping ratio due to interstitial doping processes. The results are shown in Table 1.
$\mathrm{D}=(\mathrm{k} \lambda) /(\beta \cos \theta)$,

where $\lambda$ is $\mathrm{x}$-ray wavelength, $\theta$ is Bragg's angle and $\mathrm{K}$ is the shape factor.

The Microstrain was calculated from Equation (2) $[30,31]$, resulting from the growth of the film, which in turn produced pressure and expansion in the

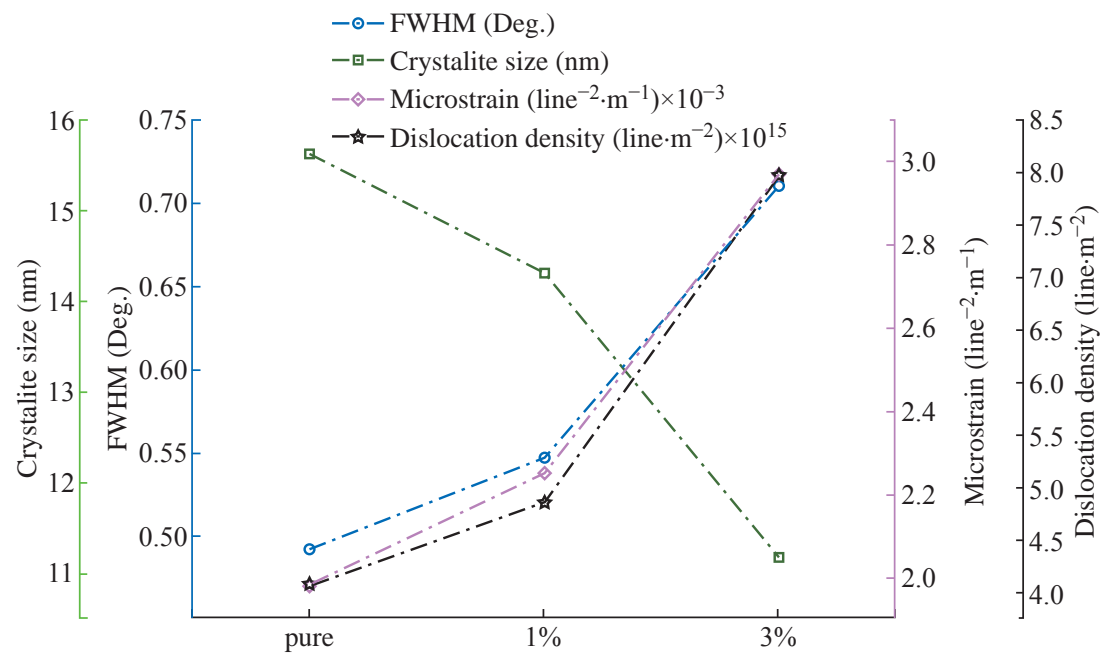

Fig. $2 \beta, \mathrm{D}, \varepsilon$ and $\delta$ of pure, $1 \%$ and $3 \% \mathrm{Mn}$ doped $\mathrm{Co}_{3} \mathrm{O}_{4}$. 
lattice. Varying the displacement of the atom based on their original location increased the microstrain $\varepsilon$. Fig. 2 shows the increase in doping ratio leading to an increase in microstrain, which was caused by the decrease in crystallinity of the film.

$\varepsilon=\beta / 4 \cos \theta$,

Equation (3) was used to calculate the dislocation density $\delta$; Fig. 2 displays the dislocation density increasing as $\mathrm{Mn}$ concentration increased, which agreed with the results obtained in previous studies [32, 33].

$$
\delta=1 / \mathrm{D}^{2},
$$

The results of $\varepsilon$ and $\delta$ values are listed in Table 1.

Topography of pure and Mn-doped $\mathrm{Co}_{3} \mathrm{O}_{4}$ films was calculated by AFM (Fig. 3). The roughness, RMS and average grain size were also collected from 2D images.

Table 1 Structural factors of $\mathrm{Co}_{3} \mathrm{O}_{4}$ : Mn thin films prepared SPT

\begin{tabular}{|c|c|c|c|c|c|c|c|}
\hline Sample & Plane (hkl) & $2 \theta\left(^{\circ}\right)$ & $\begin{array}{c}\text { Lattice constant } \\
\text { A }(\AA)\end{array}$ & B (Rad) & $\mathrm{D}(\mathrm{nm})$ & $\begin{array}{c}\varepsilon \\
\left(\text { line }^{-2} \cdot \mathrm{m}^{-1} \cdot 10^{-3}\right)\end{array}$ & $\begin{array}{c}\delta \\
\left(\text { line. } \mathrm{m}^{-2} \cdot 10^{15} \text { ) }\right.\end{array}$ \\
\hline Pure & (311) & 36.92 & 8.98 & 0.492 & 15.62 & 1.98 & 4.10 \\
\hline $1 \%$ & (311) & 37.02 & 8.121 & 0.547 & 14.32 & 2.25 & 4.88 \\
\hline $3 \%$ & (311) & 37.12 & 8.123 & 0.711 & 11.20 & 2.97 & 7.97 \\
\hline
\end{tabular}
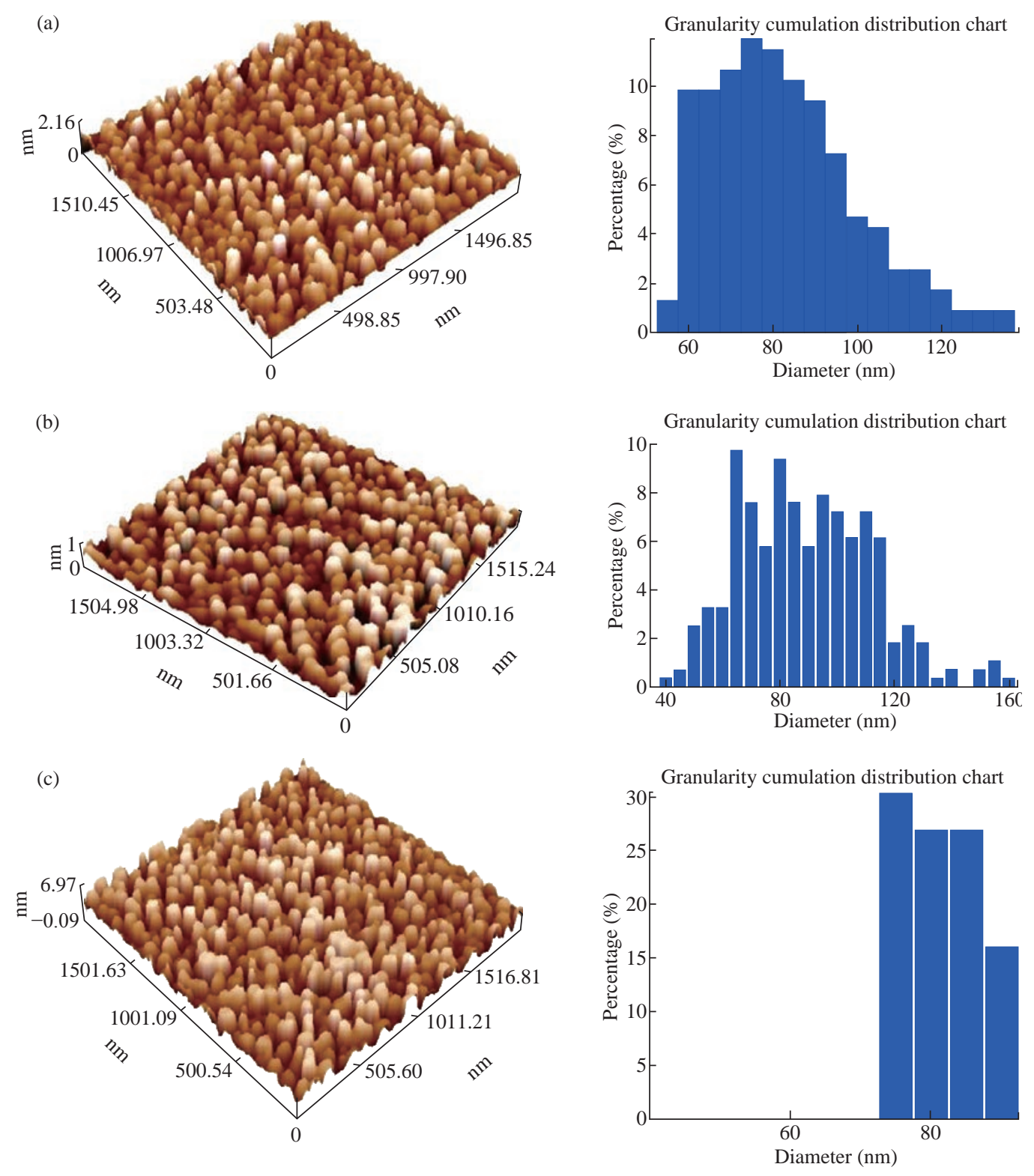

Fig. 3 AFM image of (a) pure $\mathrm{Co}_{3} \mathrm{O}_{4}$, (b) $1 \%$ and (c) $3 \%$ Mn doped $\mathrm{Co}_{3} \mathrm{O}_{4}$. 
In Fig. 3, a clear variation in morphology of Mn-doped $\mathrm{Co}_{3} \mathrm{O}_{4}$ films as $\mathrm{Mn}$ dopant concentration was increased. The AFM images of the pure $\mathrm{Co}_{3} \mathrm{O}_{4}$ showed that the particle size was regular in shape with a maximum RMS roughness of $0.431 \mathrm{~nm}$. RMS roughness acts as the standard deviation, which is important to describe surface roughness by statistical methods. As the Mn dopant increased from 1\% to 3\% (Fig. 3(b) and (c)), the columnar growth enclosed grains with a rod profile could be affected by the merger of $\mathrm{Mn}$ on the developing surface. The spreading of the crystallites on surface morphology was uniform with decreases in the RMS from $1.36 \mathrm{~nm}$ to $1.23 \mathrm{~nm}$ as the Mn concentration increased from $1 \%$ to $3 \%$. Apart from that, the average diameter decreased from $86 \mathrm{~nm}$ to 76 $\mathrm{nm}$ due to decomposition in the lattice.

The optical transmittance of undoped and $\mathrm{Mn}$ doped $\mathrm{Co}_{3} \mathrm{O}_{4}$ films was measured by UV-Vis spectrophotometer. The first beam passed through the undoubted substrate while the second beam passed through the thin film. The transmittance depended strongly on Mn concentration as shown in Fig. 4. The transmittance of the undoped $\mathrm{Co}_{3} \mathrm{O}_{4}$ film approached $48 \%$ in the near-IR spectrum. Fig. 4 demonstrated lower transmittance of $38 \%$ to $33 \%$ with the increase of doping concentration from $1 \%$ to $3 \%$, respectively. The decrease in surface roughness with increasing doping concentration is shown in Fig. 4(a)-(c). Fig. 4(d) represents the absorption values that were observed to increase with increasing doping concentration that could be related to the doped thin films that could absorb light in a broader range of wavelengths and operate extra light energy than $\mathrm{Co}_{3} \mathrm{O}_{4}$ thin film. The absorption spectrum took exponential decay with increasing wavelength due to the low energy of the falling photons and their inability to lift electrons from the valence band to the conduction band (Fig. 4(d)).

The values of the energy gap depended on the precise structure of the deposition membrane on the arrangement and distribution of atoms in the crystalline bond [34]. Cobalt oxide compounds have a direct and indirect energy gap [35] and may vary depending on the type of deposition or conditions. Fig. 5(a)-(c) shows the graph of $(\alpha h v)^{2}$ vs E (eV) for direct energy bandgap of pure and Mn-doped $\mathrm{Co}_{3} \mathrm{O}_{4}$ thin film. The value obtained for the energy gap of the cobalt oxide of $1.435 \mathrm{eV}$ differed from the standard value of $1.419 \mathrm{eV}$ [36]. This difference in the value of energy gap could be achieved by deposition mechanisms or conditions accompanying this deposition. Fig. 5(a) and (b) shows a decrease in the energy gap values from $1.419 \mathrm{eV}$ to $1.367 \mathrm{eV}$ with the increase of $\mathrm{Mn}$ concentration from $1 \%$ to $3 \%$, respectively. This might be due to a decrease in crystallite size values calculated from the X-ray diffraction pattern and the atomic force microscope, which led to crystallization weakness [37].

Absorption coefficient $(\alpha)$ can be defined through Equation (4). $\alpha$ decreased with increases of $\lambda$

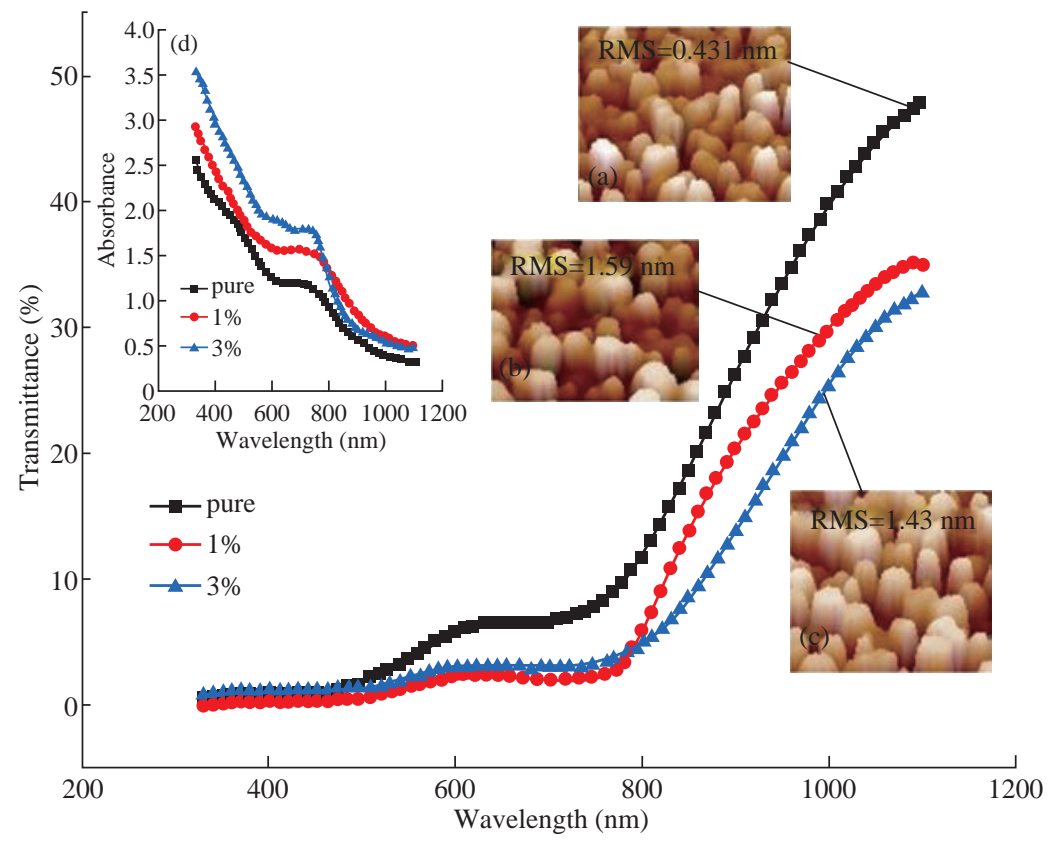

Fig. 4 Optical spectrum transmittance of $\mathrm{Co}_{3} \mathrm{O}_{4}$ : Mn: (a)-(c) 3D image for pure, $1 \%$ and $3 \% \mathrm{Mn}$ doped $\mathrm{Co}_{3} \mathrm{O}_{4}$, respectively; (d) spectrum absorption of $\mathrm{Co}_{3} \mathrm{O}_{4}: \mathrm{Mn}$. 

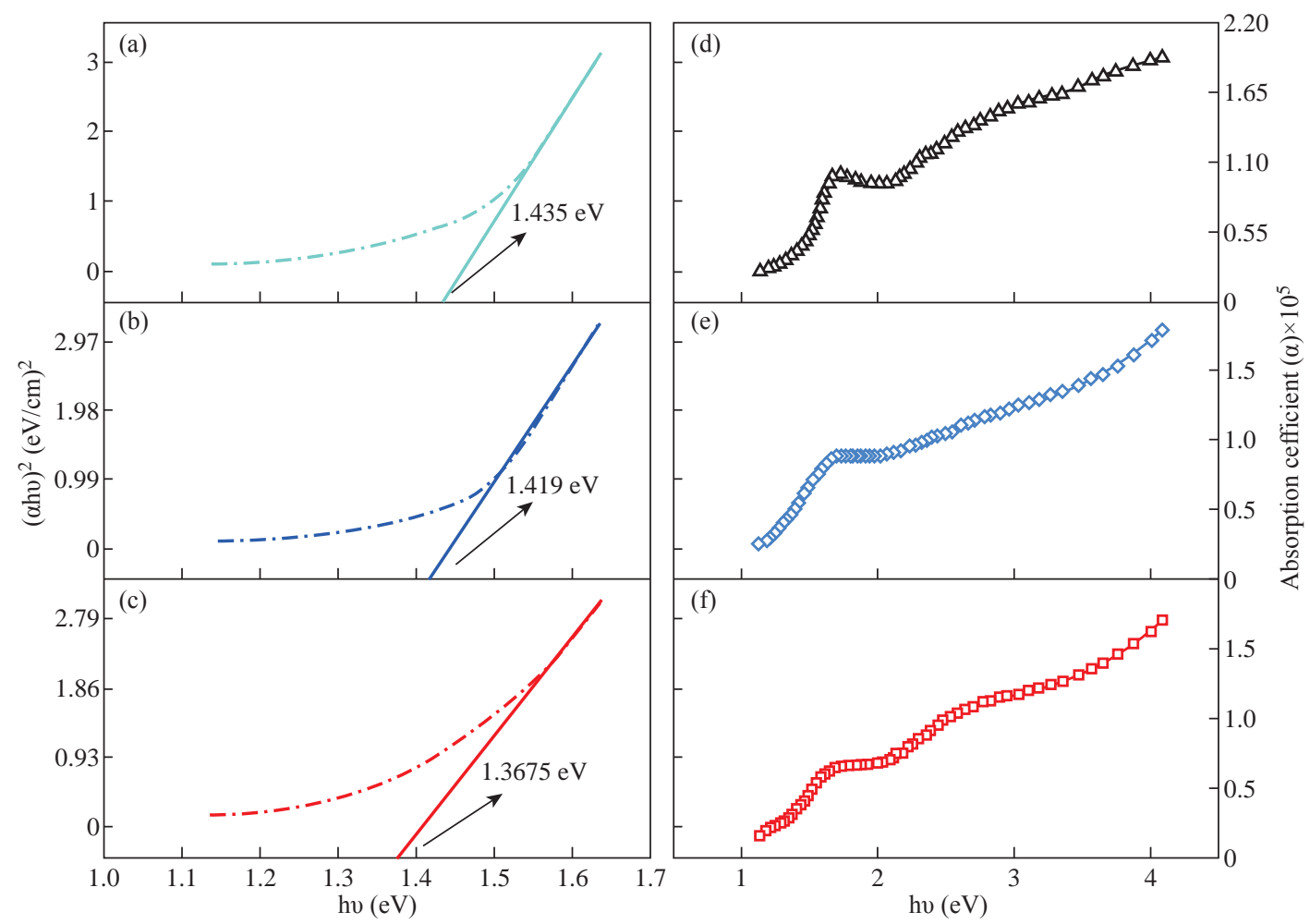

Fig. 5 (a)-(c) The optical energy gap of pure, $1 \%$ and $3 \%$ Mn doped $\mathrm{Co}_{3} \mathrm{O}_{4}$, respectively; (d)-(f) the absorption coefficient of pure, $1 \%$ and $3 \% \mathrm{Mn}$ doped $\mathrm{Co}_{3} \mathrm{O}_{4}$, respectively.

increases (Fig. 5(d)-(f) due to an increase in the Mn concentration leading to an increase in $\mathrm{Mn}^{2+}$ ions [38]. $\alpha$ was obtained utilizing the following Equation (4) [39]:

$\alpha=2.303 \mathrm{~A} / \mathrm{t}\left(\mathrm{cm}^{-1}\right)$,

where $t$ is the film thickness.

The refractive index (n) is shown in Fig. 6, calculated from reflectance (R) via Equation (5) [40]. The study of refractive index obtained a clear picture of

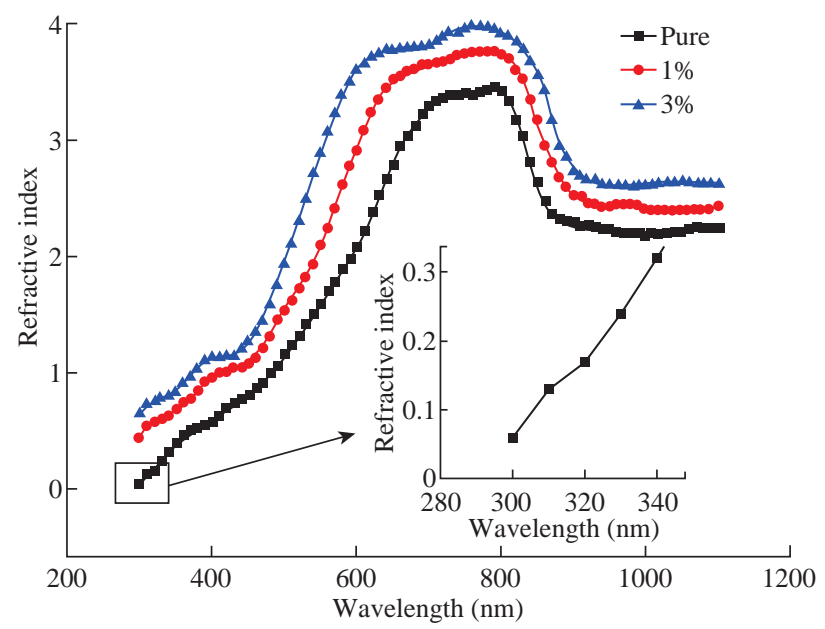

Fig. 6 The refractive index of pure and $\mathrm{Mn}$ doped $\mathrm{Co}_{3} \mathrm{O}_{4}$, deposited by the spray pyrolysis technique. the properties and visual behavior of the films recorded for the pure film's refractive index values of 2.6 which were taken down to 2.4 then to 2.3 with an increase in dopant concentration from $1 \%$ to $3 \%$, respectively, due to the increased density of the medium, besides the scattering of the incident light at the grain boundaries [41].

$\mathrm{n}=(1+\sqrt{R}) /(1-\sqrt{R})$.

Fig. 7 represents the dynamic resistance change as a function of time for several $\mathrm{NO}_{2}$ gas concentrations (200, 400, 600, and $800 \mathrm{ppm})$ at operating temperature of $200{ }^{\circ} \mathrm{C}$ for $\mathrm{Co}_{3} \mathrm{O}_{4}$ and $\mathrm{Mn}$ doped $\mathrm{Co}_{3} \mathrm{O}_{4}$. It was noted that the resistance values were limited to $5-45 \mathrm{k} \Omega . \mathrm{m}$; the greatest resistance was recorded in the presence of air $\mathrm{R}_{\mathrm{a}}$ for the undoped samples; the resistance values decreased with the doping ratio due to increasing number of charge carriers. The resistance of the sample decreased with increasing gas concentration from 200 to $800 \mathrm{ppm}$, which can be due to surface roughness. All recorded samples had a negative connection feature, a decrease in resistance with an increase in concentration of $\mathrm{NO}_{2}$ gas. When $\mathrm{O}_{2}$ molecules are adsorbed on the surface of metal oxides (Fig. 7(b)), which leads to the capture of electrons from the conduction band $\left(E_{c}\right)$, the electrons are held on the surface of the films 


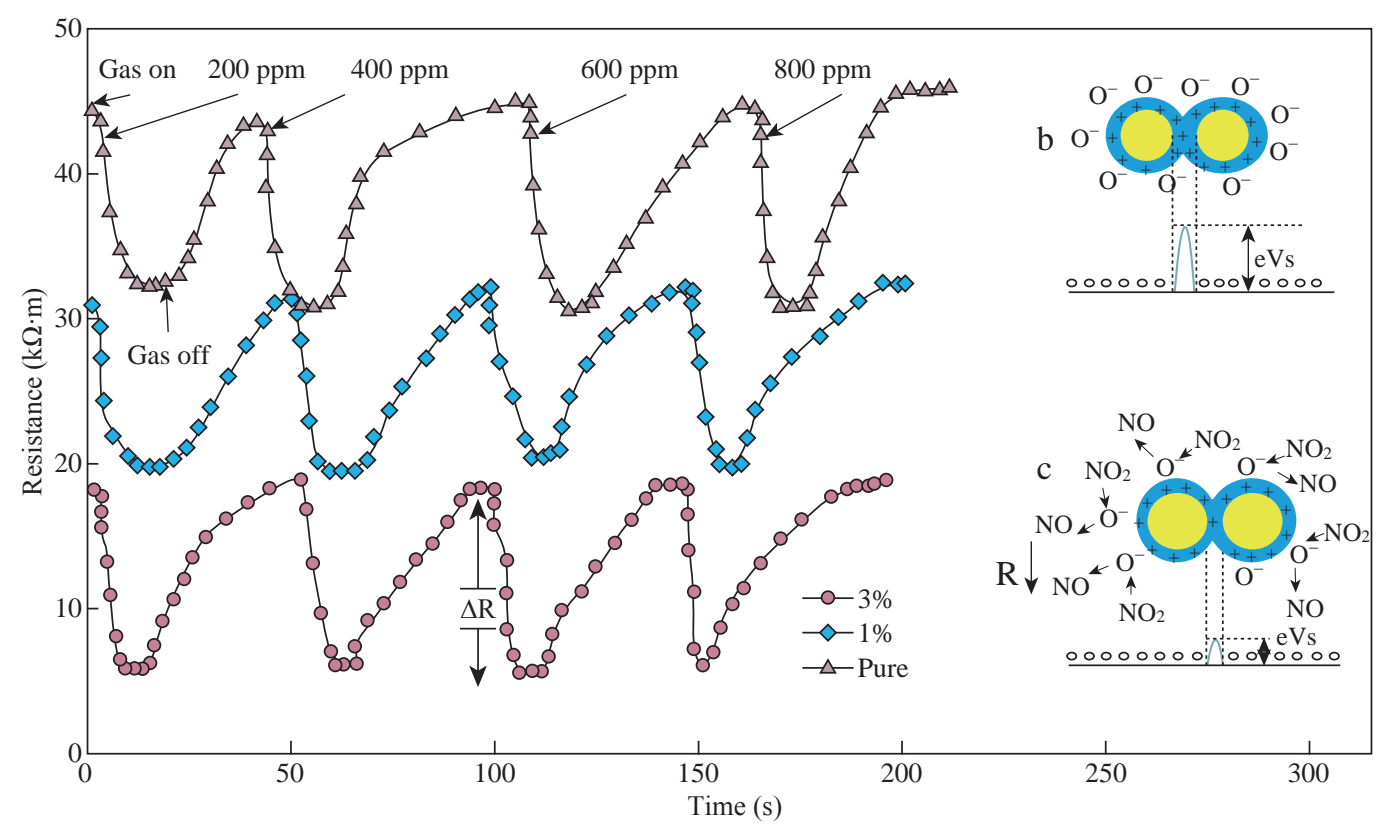

Fig. 7 Resistance change as a function of time of $\mathrm{Co}_{3} \mathrm{O}_{4}$ : Mn films for changed concentrations of $\mathrm{NO}_{2}$ gas at a working temperature $150^{\circ} \mathrm{C}$.

as models $\left(\mathrm{O}^{-}, \mathrm{O}^{-2}, \mathrm{O}_{2}^{-}\right)$. This will raise an electrondepleted region. The electron-depleted region is called the space-charge layer, of which thickness is the length of the band bending region. The interaction of these components with oxidizing gas or competitive adsorption and replacement of the adsorbed oxygen by other molecules decreases, and can reverse the band bending, resulting in a decrease in depletion region of the $\mathrm{Co}_{3} \mathrm{O}_{4}$ : Mn gas sensor as reacting with $\mathrm{NO}_{2}$ gas and extend in the depletion layer as $\mathrm{Co}_{3} \mathrm{O}_{4}: \mathrm{Mn}$ reacting with reduced gas Fig. 7(c).

Fig. 8 represents the sensitivity percentage values

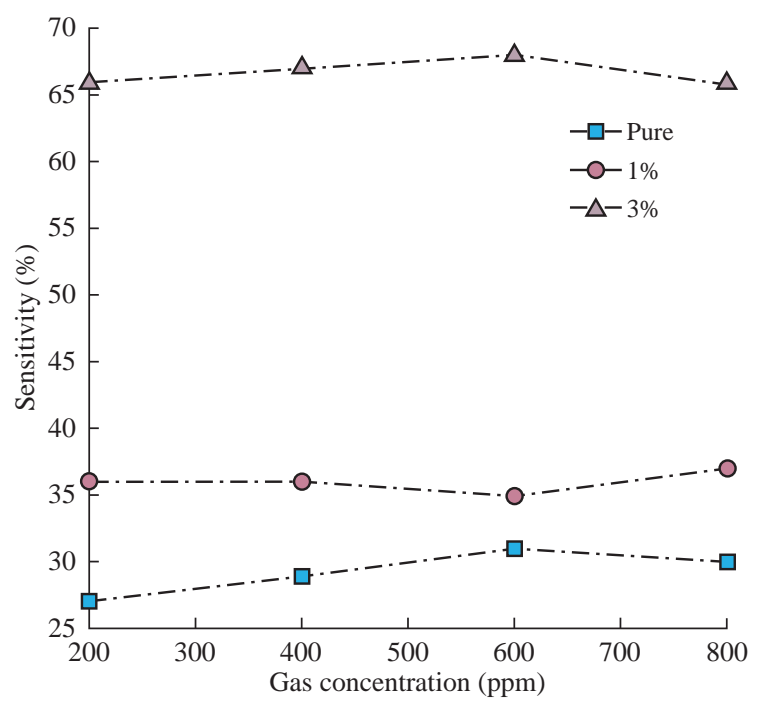

Fig. 8 Percentage sensitivity change of $\mathrm{Co}_{3} \mathrm{O}_{4}$ : $\mathrm{Mn}$ films for changed concentrations of $\mathrm{NO}_{2}$ gas at a working temperature of $150{ }^{\circ} \mathrm{C}$. calculated from Equation (6) [42]. Fig. 7 depicts $\mathrm{Co}_{3} \mathrm{O}_{4}$ : Mn films that deposited on the glass by the SPT method at an operating temperature of $200{ }^{\circ} \mathrm{C}$ as a function of $\mathrm{NO}_{2}$ gas concentrations. It could be seen that the highest percentage sensitivity was sample doped with $\mathrm{Mn}$ of $3 \%$, which was about $65 \%$, possibly due to the increase in the number of charge carriers of holes owing to the doping and the increase in crystallite size, reducing the depletion layer and potential barrier.

Sensitivity $=\Delta R / R_{a}=\left|\left(R_{a}-R_{g}\right) / R_{a}\right| \times 100 \%$,

where $R_{a}$ is resistance of the film sensor in the presence of air, and $\mathrm{R}_{\mathrm{g}}$ resistance of the film in $\mathrm{NO}_{2}$ gas.

Fig. 9(a) represents the response time as a function of gas concentration of $\mathrm{NO}_{2}$. It was observed the minimum response time was in the $3 \%$ doping concentration, and at the concentration of the gas 800 $\mathrm{ppm}$, it was about $4 \mathrm{~s}$. (Reducing time is a good feature of sensors.) In general, the response time decreased with the increase of gas concentration, which could be due to the increased charge carrier concentration by adsorption and absorption of the gas to the surface.

Fig. 9(b) represents the recovery time or return time as a function of $\mathrm{NO}_{2}$ gas concentrations, where the minimum recovery time of the $1 \%$ model was equal to $10 \mathrm{~s}$ (Reducing time is a good feature of sensors). This occurred due to the deforming of films at $150{ }^{\circ} \mathrm{C}$. Continuous exposure to operating temperature caused the film properties to change with the change of gas sensing properties [43]. 

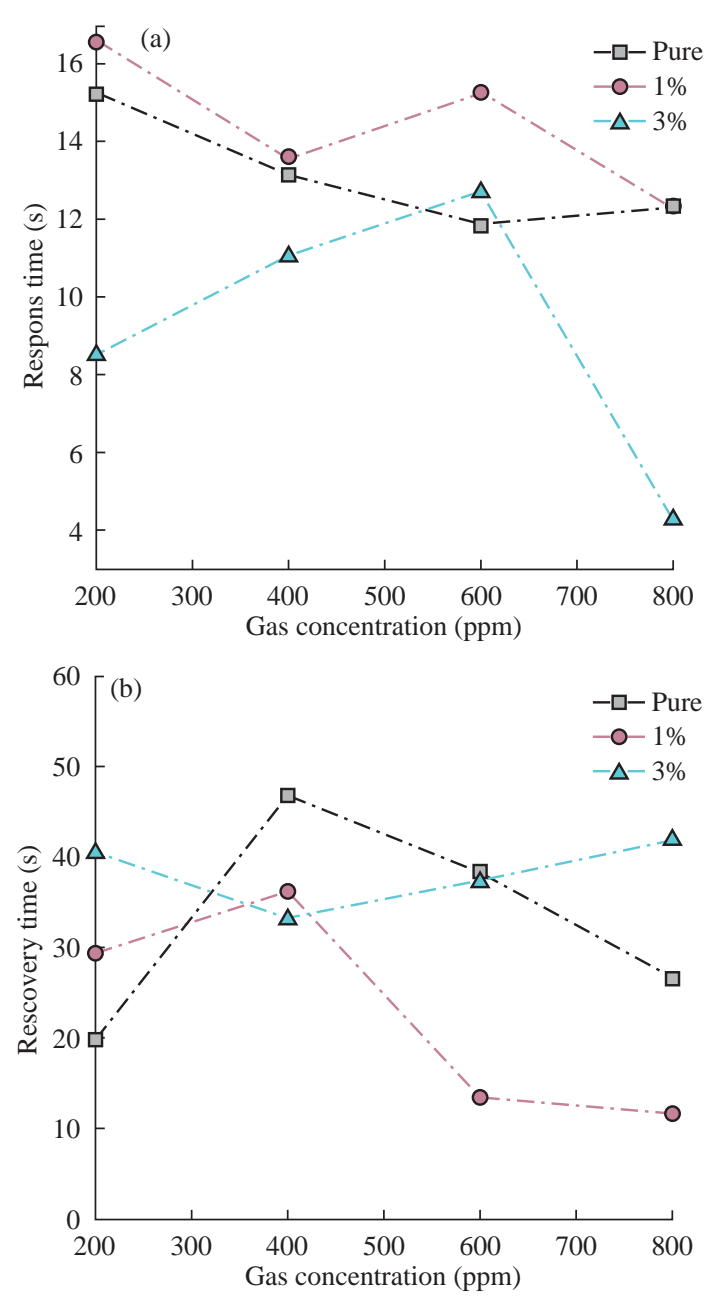

Fig. 9 (a) Response time and (b) recovery time. Change of $\mathrm{Co}_{3} \mathrm{O}_{4}$ : Mn films for different concentrations for $\mathrm{NO}_{2}$ gas at a working temperature $150^{\circ} \mathrm{C}$.

\section{Conclusions}

Undoped and Mn-doped $\mathrm{Co}_{3} \mathrm{O}_{4}$ were produced by the SPT. The structural description of the samples studied by XRD displayed polycrystalline with cubic structure; the crystallite size reduced from $15.62 \mathrm{~nm}$ for the pure $\mathrm{Co}_{3} \mathrm{O}_{4}$ to $11.2 \mathrm{~nm}$ upon 3\% Mn-doped $\mathrm{Co}_{3} \mathrm{O}_{4}$ samples. The morphology investigation by AFM showed a columnar growth containing grains with a rod shape, which can be caused by a combination of $\mathrm{Mn}$ on the developing surface. The incorporation of $\mathrm{Mn}$ into $\mathrm{Co}_{3} \mathrm{O}_{4}$ weakened the energy band due to the formation of surface-associated defects in the nanoparticles. We concluded that the electrical resistance of the films were reduced from $45 \mathrm{k} \Omega$ to 18 $\mathrm{k} \Omega$ with the increasing of doping rate, and that the best sensitivity to the gas $\mathrm{NO}_{2}$ was $65 \%$ by $3 \% \mathrm{Mn}$ content. With the concentration of gas $800 \mathrm{ppm}$ at a temperature of $150{ }^{\circ} \mathrm{C}$, the best recovery time was $10 \mathrm{~s}$, and the best response time was $4 \mathrm{~s}$ to the doped film by $3 \%$, with the concentration of gas $800 \mathrm{ppm}$ at a temperature of $150{ }^{\circ} \mathrm{C}$.

\section{Acknowledgments}

This study was completed with the help of Mustansiriyah University, College of Science, physics department, and college of Education, physics department.

\section{Conflict of Interests}

The authors declare that no competing interest exists.

\section{References}

[1] M. Basit, N. Shah, S. Ali, et al., Cobalt Doping Effects on Zinc Oxide Transparent Conducting Thin Films. World Applied Sciences Journal, 2014, 32(8): 1664-1670.

[2] S.S. Chiad, H.A. Noor, O.M. Abdulmunem, et al., Optical and Structural properties of Ni-doped $\mathrm{Co}_{3} \mathrm{O}_{4}$ Nanostructure Thin films Via CSPM. IOP Conf. Series: Journal of Physics: Conf. Series 1362, 2019: 012115.

[3] K. Sugiura, H. Ohta, K. Nomura, et al., Thermoelectric properties of epitaxial films of layered cobalt oxidesfabricated by topotactic ion-exchange methods. International Conference on Thermoelectrics, IEEE, 2006, 1: 4244-0811.

[4] G. Calin, M. Irimia, C. Scarlat, et al., Synthesis and characterization of nickel cobalt oxide thin films. CAS 2010 Proceedings (International Semiconductor Conference), 2010, 978(1): 4244-5781.

[5] R .Chikwenze, P. Nwofe, P. Agbo, et al., Annealing effects and film thickness dependence of cobalt selenide thin films grown by the chemical bath deposition method. IOSR-JECE, 2015,10(5): 19-24.

[6] İ. Kariper, T. Özpozan, Optical properties of cobalt xanthate films on different substrates. International Journal of Minerals, Metallurgy and Materials, 2014, 21(7): 736-740.

[7] G. Kandalkar, C. Lokhande, R. Mane et al., A nonthermal chemical synthesis of hydrophilic and amorphous cobalt oxide films for super capacitor application. Applied Surface Science, 2007, 253: 3952-3956.

[8] M. Rad, M.T. Aan, and M. Alavi, Effect of incubation time, $\mathrm{CuSO}_{4}$ and Glucose concentrations on biosynthesis of copper oxide $(\mathrm{CuO})$ nanoparticles with rectangular shape and antibacterial activity: Taguchi method approach. Nano Biomed. Eng., 2018, 10(1) : 25-33.

[9] M. Alavi, M. Rai, Recent advances in antibacterial applications of metal nanoparticles (MNPs) and metal nanocomposites (MNCs) against multi drug resistant (MDR) bacteria. Expert Review of Anti-infective Therapy, 2019.

[10] M. Alavi, N. Karimi, Biosynthesis of Ag and $\mathrm{Cu}$ NPs by secondary metabolites of usnicacid and thymol with biological macromolecules aggregation and antibacterial activities against multi drug resistant (MDR) bacteria. Int J Biol Macromol., 2019, 1: 128:893-901.

[11] G. Kandalkar, L. Hae-Min, C Heeyeop et al., Structural, morphological, and electrical characteristics of the electro deposited cobalt oxide electrode for super capacitor applications. Materials Research Bulletin, 2011, 46: 48- 
51.

[12] R. Gupta, K. Ghosh, and P. Kahol, Room temperature ferromagnetic multilayer thin film based on indium oxide and iron oxide for transparent spintronic applications. Materials Letters, 2010, 64: 2022-2024.

[13] K. Ravichandran, K. Karthika, B. Sakthivel, et al., Tuning the combined magnetic and antibacterial properties of $\mathrm{ZnO}$ nanopowders through $\mathrm{Mn}$ doping for biomedical applications. Journal of Magnetism and MagneticMaterials, 2014, 358(359): 50-55.

[14] M. Dervin, I. Buret, and C. Loisel , Easy-to-Deploy Emergency Communication System Based on a Transparent Telecommunication Satellite. First International Conference on Advances in Satellite and Space Communications IEEE, 2009, 168-173.

[15] S. Pocoví-Martínez, I. Zumeta-Dube, and D. Diaz, Production of Methanol from Aqueous $\mathrm{CO}_{2}$ by Using $\mathrm{Co}_{3} \mathrm{O}_{4}$ Nanostructures as Photocatalysts, Journal of Nanomaterials Volume. Article ID, 2019, 6461493, 10, https://doi.org/10.1155/2019/6461493

[16] S. Kandalkar, J. Gunjakar, and C. Lokhande, Preparation of cobalt oxide thin films and its use in super capacitor application. Applied Surface Science, 2008, 254: 55405544.

[17] S. Mu, Z. Wu, Y. Wang, et al., Formation and characterization of cobalt oxide layers on polyimide films via surface modification and ion-exchange technique. Thin Solid Films, 2010, 518: 4175-4182.

[18] J. Tyczkowski, R. Kapica, and J. Łojewska, Thin cobalt oxide films for catalysis deposited by plasma-enhanced metal-organic chemical vapor deposition. Thin Solid Films, 2007, 515: 6590-6595.

[19] A. Jayatissa, K. Guoa, A. Jayasuriya, et al., Fabrication of nanocrystalline cobalt oxide via sol-gel coating. Materials Science and Engineering, 2007, B, 144: 69-72.

[20] S. Jogade, D. Sutrave, and V. Patil, Structural and Morphological Properties of Mn Doped $\mathrm{Co}_{3} \mathrm{O}_{4}$ ThinFilm Deposited by Spin Coat Method. Int. Engineering Research and Application, 2016, 6(9): 41-46.

[21] J. Shan, R. Dai, Cobalt oxide thin film prepared by an electrochemical route for Li-ion battery. Journal of Power Sources, 2009, 189: 204-210.

[22] A. Balati, Heterojunction of $\mathrm{TiO}_{2}$ nanoparticle embedded into ZSM5 to 2D and 3D layered structures of $\mathrm{MoS}_{2}$ nanosheets fabricated by pulsed laser ablation and microwave technique in deionized water: structurally enhanced photocatalytic performance. Applied Nanoscience, 2018: 1-14.

[23] A. Balati, S. Tek, K. Nash, et al., Nanoarchitecture of $\mathrm{TiO}_{2}$ microspheres with expanded lattice interlayers and its heterojunction to the laser modified black $\mathrm{TiO}_{2}$ using pulsed laser ablation in liquid with improved photocatalytic performance under visible light irradiation. Journal of Colloid and Interface Science, 2019, 541: 234248.

[24] A. Balati, B. Arianne, A. Shahriar, et al., Simultaneous formation of ultra-thin $\mathrm{MoSe}_{2}$ nanosheets, Inorganic Fullerene-Like $\mathrm{MoSe}_{2}$ and $\mathrm{MoO}_{3}$ quantum dots using fast and ecofriendly Pulsed Laser Ablation in Liquid followed by microwave treatment. Materials Science in Semiconductor Processing, 2019, 99: 68-77.

[25] A. Kaphle, T. Reed, A. Apblett, et al., Doping Efficiency in Cobalt-Doped ZnO Nanostructured Materials. Journal of Nanomaterials, 2019, 2019: 1-13.

[26] R. Venkatesh, C.R. Dhas, R. Sivakumar, et al., Analysis of optical dispersion parameters and electrochromic properties of manganese-doped $\mathrm{Co} 3 \mathrm{O} 4$ dendrite structured thin films. Journal of Physics and Chemistry of Solids, 2018, 122: 118-129.

[27] A. Saroja, I. Punithavathy, S. Jeyakumar et al., Substrate temperature influence on the optical and electrical properties of spray deposited $\mathrm{Sn}_{2} \mathrm{~S}_{3}$ thin films. Optik130, 2017: 245-225

[28] S. Petitto, E. Marsh, G. Carson, et al., Cobalt oxide surface chemistry: The interaction of $\mathrm{CoO}\left(\begin{array}{lll}1 & 0 & 0\end{array}\right), \mathrm{Co}_{3} \mathrm{O}_{4}$ (1 110$)$ and $\mathrm{Co}_{3} \mathrm{O}_{4}\left(\begin{array}{lll}1 & 1 & 1\end{array}\right)$ with oxygen and water, Journal of Molecular Catalysis A: Chemical, 2008, 281: 49-58.

[29] K. Abass, M. Mohammed, Fabrication of ZnO:Al/Si Solar Cell and Enhancement its Efficiency Via Al-Doping, Nano Biomed. Eng., 2019, 11(2): 170-177.

[30] C. Guyon, A. Barkallah, F. Rousseau,, et al., Deposition of cobalt oxide thin films by plasma-enhanced chemical vapor deposition (PECVD) for catalytic applications. Surface \& Coatings Technology, 2011, 206: 1673-1679.

[31] E. Hassan, T. Mubarak, K. Abass, et al., Structural, Morphological and Optical Characterization of Tin Doped Zinc Oxide Thin Film by (SPT). Journal of Physics: Conference Series, 2019: 1234.

[32] C. Liao, Y. Lee, H. Yu, et al., Structure characterization and electrochemical properties of RF sputtered lithium nickel cobalt oxide thin films. Electrochimica 50, 2004: 461-466.

[33] A. Khadayeir, E. Hassan, S. Chiad, et al., Structural and Optical Properties of Boron Doped Cadmium Oxide. 2019, Journal of Physics: Conference Series, 1234.

[34] S. Shi, S. Qian, X. Hou, et al., Structural and Optical Properties of Amorphous $\mathrm{Al}_{2} \mathrm{O}_{3}$ Thin Film Deposited by Atomic Layer Deposition. 2019, Advances in Condensed Matter Physics, 2018: Article ID 759897810 pages.

[35] L. Qiao, H.Y. Xiao, H.M. Meyer, et al., Nature of the band gap and origin of the electro/ photoactivity of $\mathrm{Co}_{3} \mathrm{O}_{4}$. J. Mater. Chem. C, 2013, 1: 46284633.

[36] R. Shinde, S. Mahadik, T. Guja, et al., Super capacitive cobalt oxide $\left(\mathrm{Co}_{3} \mathrm{O}_{4}\right)$ thin films by spray pyrolysis. Applied Surface Science, 2006, 252: 7487-7492.

[37] M. Pal, U. Pal, J. M. Gracia, et al., Effects of crystallization and dopant concentration on the emission behavior of $\mathrm{TiO}_{2}$ : Eu nanophosphors. Nanoscale Research Letters, 2012, 7: 1-12.

[38] V. Patil, P. Joshi, M. Chougule, et al., Synthesis and Characterization of $\mathrm{Co}_{3} \mathrm{O}_{4}$ Thin Film. Soft Nanoscience Letters, 2012, 2: 1-7.

[39] A. Alkelaby, K. Abass, T. Mubarak, et al., Effect of $\mathrm{MnCl}_{2}$ Additive on Optical and Dispersion Parameters of Poly methyl Methacrylate Films. Journal of Global Pharma Technology, 2019, 11(4): 347-352.

[40] D. Latif, S. Chiad, M. Erhayief, et al., Effects of $\mathrm{FeCl}_{3}$ additives on optical parameters of PVA. Journal of Physics: Conf. series, 2018: 1003.

[41] P. Prathap, Y. Subbaiah, M. Devika, et al., Optical properties of $\mathrm{In}_{2} \mathrm{O}_{3}$ films prepared by spray pyrolysis. Materials Chemistry and Physics, 2006, 100(2-3): 10, 375-379.

[42] P. Rambu, D. Sirbu, N. Iftimie, et al., Polycrystalline $\mathrm{ZnO}-\mathrm{In}_{2} \mathrm{O}_{3}$ thin films as gas sensors. Thin Solid Films, 2011, 520: 1303-1307.

[43] A.A. Alharbi, U. Weimar, and N. Bârsan, Gas Sensing Mechanism Investigation of $\mathrm{LaFeO}_{3}$ Perovskite-Type Oxides via Operando Technique. Proceedings, 2019, 14: 51.

Copyright ${ }^{\complement}$ Ehssan Salah Hassan, Kameran Yasseen Qader, Esraa Hassn Hadi, Sami Salman Chiad, Nadir Fadhil Habubi, and Khalid Haneen Abass. This is an open-access article distributed under the terms of the Creative Commons Attribution License, which permits unrestricted use, distribution, and reproduction in any medium, provided the original author and source are credited. 